\title{
OPTIMAL WATER ALLOCATION BY EQUILIBRATING BETWEEN AGRICULTURAL AND ENVIRONMENTAL SECTORS IN RIVER BASINS
}

\author{
TAREBARI, H. ${ }^{1}-$ JAVID, A. H. ${ }^{1 *}$ - MiRBAGHERI, S. A. ${ }^{2}-$ FAHMI, H. ${ }^{3}$ \\ ${ }^{I}$ Department of Environmental Engineering, Science and Research Branch, Islamic Azad \\ University, Tehran, Iran \\ (phone: +98-914-353-6802) \\ ${ }^{2}$ Department of Civil and Environmental Engineering, K. N. Toosi University of Technology \\ Tehran, Iran \\ ${ }^{3}$ Ministry of Energy (MOE), Tehran, Iran \\ *Corresponding author \\ e-mail: a.javid@srbiau.ac.ir; phone: +98-214-486-2622; fax: +98-214-486-8539
}

(Received 6 ${ }^{\text {th }}$ May 2018; accepted $17^{\text {th }}$ Jul 2018)

\begin{abstract}
The aim of this study was to optimal surface water resource management in the river-lake connected basins which are faced with water scarcity. In these regions, meeting the water demands of stakeholders along with supplying the environmental water requirements are critical and controversial issues. In this research, a multi-objective water allocation model which addresses the socio-economic and environmental objectives was developed, and a new simple method has been introduced for equilibrating between the sectors among which there are main conflicts. The proposed method was examined in the Zarrineh and Simineh rivers basins in Iran. These basins are the main surface water suppliers of the Lake Urmia which is facing a shrinkage challenge. As the agricultural sector is the main water user in the Lake Urmia basin, so there are significant conflicts between this sector and Lake Urmia's environment. Hence, the equilibrium status is obtained between these two stakeholders through drawing the graph of their utility functions versus risk parameter in the compromise programming technique. The proposed model can supply the domestic, industrial and agricultural demands 92.3, 100 and 60.8\% respectively. Moreover, the ecological requirements of the rivers are supplied totally, and that of Lake Urmia amounts to $67.45 \%$.
\end{abstract}

Keywords: agricultural water, compromise programming, environmental demand, Lake Urmia, multiobjective optimization

\section{Introduction}

Water scarcity is one of the crucial challenges in the arid and semi-arid areas. Many regions of Iran have encountered this problem. This issue is mainly due to an increment in water consumption, mismanagement of resources and the impact of climate change (Abbaspour et al., 2009; Madani, 2014; Shakib and Shojarastegari, 2017). One of Iran's major basins is the Lake Urmia basin in the northwest of Iran. In the recent years this region has been confronted with a significant decrease in water resources, such that, the volume of runoffs in this catchment area has reduced considerably during the past years, thereby, resulting in a decline in the surface area and level of the Lake Urmia (AghaKouchak et al., 2015; Alipour and Olya, 2015; Hassanzadeh et al., 2012). Under such conditions, the adoption of an optimal approach towards a sustainability of water resources is extremely essential. In accordance with the views of several experts, in relative to the sustainable management of water resources, three key factors in the minimum must be considered; and these are the socio-economic and environmental 
aspects (Braga, 2001; Poff et al., 2015; Zarghami and Szidarovszky, 2011). Hence, various studies have been performed based on multi-objective optimization models to consider different goals and reach sustainability (Oxley et al., 2016; Roozbahani et al., 2015; Xuan et al., 2012).

In order to address all the objectives simultaneously in the management process, the multi-objective optimization models have been widely applied and solved by the use of different methods like distance-base approaches (Zarghami and Szidarovszky, 2011). These methods attempt to minimize the distance of each solution from the ideal one or maximize from the worst (anti-ideal) response (Kao, 2010). In the present study, compromise programming $(\mathrm{CP})$ technique as one of the mentioned methods is utilized to solve the proposed model.

In order to maintain sustainability in the ecosystem, efforts to balance the environmental flows with other competitive sectors are necessary (Acreman et al., 2014). Thereby, meeting the environmental requirements along with the water demands supplying is one of the most critical objectives for the optimal and sustainable allocation of water resources and also have been focused in the current study. In some of the studies, this aim has been supplemented as a constraint (Roozbahani et al., 2013; Yang and Yang, 2013) whereas, in others, it is in the form of an objective function (Mao et al., 2016). In this research, efforts have been made to supply simultaneously the environmental demand of the Lake Urmia and various water demands as well as considering relative priorities of water consumption sectors. With due attention to the fact that, climate change in most parts of the globe, has led to a decrease in water resources (IPCC, 2007; Stocker et al., 2013), accordingly in order to conserve the ecosystem of rivers and sustainability of water resources, assessing the impact of climate change and its implications in the management of water resources is imperative (Emam et al., 2015; Jiang et al., 2012; Lee et al., 2018; Omer et al., 2017). Hence, in this paper, the results of previous studies about climate change impacts on the runoff in the Simineh and Zarrineh rivers basins are considered (UNDP, 2016). In addition to climate change, human activities especially agricultural development also plays an important role in surface runoff volumes (Aghakhani et al., 2018; Barnett et al., 2008; Scanlon et al., 2007; $\mathrm{Xu}$ et al., 2013). Also one of the main characteristics of this research is determining the amount of agricultural consumption with respect to raise the environmental demand satisfying to the desirable level. As regards the amount of water available, it is limited in the semiarid areas, so competitions amongst the various stakeholders and appearance of disagreements are inevitable. Also, the various researchers have often utilized conflict resolution techniques based on the game theory, which include cooperative and non-cooperative game methods to resolve disagreements (Bazargan-Lari et al., 2009; Madani et al., 2014; Mianabadi et al., 2014; Salazar et al., 2007). But in this research, a new and simple way is introduced to reduce the competition and reach an agreement between the agricultural sector (as a major consumer of water) and Lake Urmia (as an environmental stakeholder), in which the final approach has been obtained by finding a suitable amount of risk parameter - as a term of $\mathrm{CP}$ equation-and selecting appropriate weight coefficients for objective functions. It should be noted that, determining of relative importance or weights for various objectives in the decision-making process of water resource management is an importance and an implicit issue (Can and Houck, 1984; Prakash et al., 2015), so the introduced method can be helpful in this regard. 
In the above-mentioned method, the optimal equilibrium point between the agricultural and environmental sectors is determined which indicates the largest equal satisfaction (utility) level for both sides. Furthermore, water demand increase because of the population growth and water resource development in the future is considered in this research. The formulation of the model and objective functions, as well as the equilibrating process, is entirely described hereunder.

\section{Study area and data}

The Zarrineh and Simineh rivers, which are located in the northwest of Iran are about 300 and $200 \mathrm{~km}$ in length respectively. These two rivers supply a crucial portion of the surface inflows to Lake Urmia, such that, for the past 60 years, more than half of the surface water resources of the lake were provided by these rivers. The average longterm surface water resources of the Zarrineh river basin are 2590 million $\mathrm{m}^{3}$ and the surface water resources of the Simineh river basin are 655 million $\mathrm{m}^{3}$. The Martyr Kazemi Dam, with the active volume of 654 million $\mathrm{m}^{3}$, is the largest dam of the Lake Urmia Basin, which is situated on the Zarrineh River and is most vital in supplying the different sectors requirements in the sub-basin of this river. Similarly, the two dams, Sarough and Cheraghveis, which have also been constructed on the major tributaries of Zarrineh River, will soon be exploited (MGC, 2012). Moreover, due to the Lake's drying up over the past two decades, meeting its environmental water requirements is crucial and the main sources for such a supply are the two mentioned rivers. One of the imperative complexities in this basin is the reduction of runoff inputs to the Lake Urmia and water consumption increasing, particularly, in the agricultural sector (ULRP, 2015). Moreover studies demonstrate that climate change in the Zarrineh and Simineh rivers sub-basins has caused a reduction of the volume of water inflows, such that according to Iran's Third National Communication report to UNFCCC, $21 \%$ decrease in the average volume of runoffs in the case study area within the period of 2015-2045 in comparison with the long-term average under the pessimistic scenario, could be assumed due to climate change impacts (UNDP, 2016). With due attention to the high consumption (of water) in the agricultural sector of the Lake Urmia basin and its low efficiency, in order to supply the lake's demand, the water consumption volume in the agricultural sector, must be reduced by a considerable amount. In fact, the most critical competition is between the agricultural sector and the lake's environment. Figure 1 illustrates the schematic of the sub-basins of Zarrineh River and Simineh River including the location of their reservoirs, water inflows and demand points.

In this research, the water resource allocation model has been developed, based on long-term average data and the schematic of the case study area has been shown in Figure 1. The amount of surface water resources in the catchment area is based on the National Water Master Plan Study of Lake Urmia Basin (MGC, 2012) and according to the report on the impacts of climate change in the studied sub-basins (UNDP, 2016). In fact, the inflows' water volume in the modeling process is assumed $79 \%$ (i.e. $21 \%$ decrease) of the long-term (60 years) average values. The water demand in the domestic, industrial, and agricultural sectors are also based on the estimated demand amount for the year 2041, as well as dams which will be under operation at that time are considered in the modeling process. Also, the ecological demands of rivers have been calculated by the modified Montana Method, approved by the Iranian Ministry of Energy (Torabi Palatkaleh et al., 2010). 


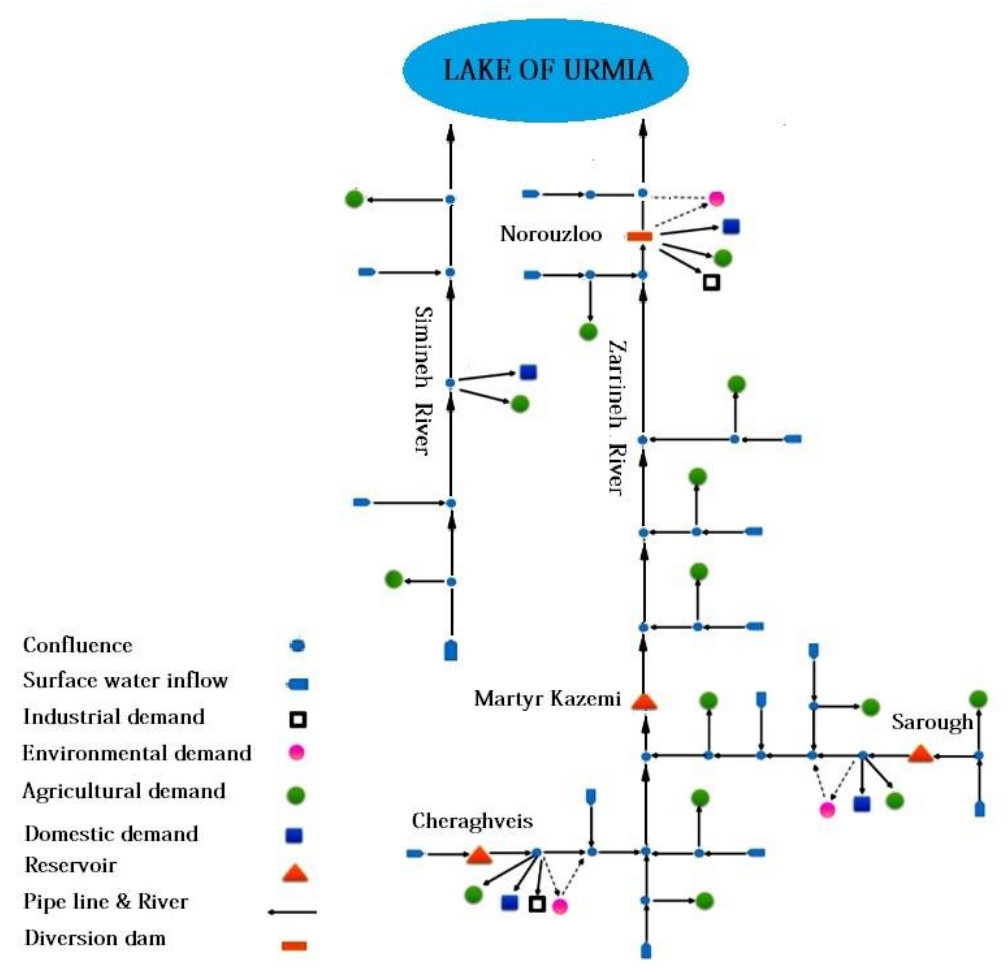

Figure1. Schematic of the southern region of Lake Urmia basin (sub-basins of Zarrineh and Simineh rivers)

\section{Methods}

In order to provide a sustainable approach in the management of surface water resources, various aspects of water resource management including the environmental and socio-economic aspects have been considered in the process of the proposed multiobjective optimization model. The model's goals have been implemented using the objective functions as well as the various constraints in the modeling. The water allocation modeling is principled on the status of the catchment area network, as presented in Figure 1, and also by using the various equations that will be introduced in the follows. The environmental water requirements of the rivers have been identified as a demand node in the downstream of each dam, in respect to its return flow proportion to the river, is equal to one. In continuation, the formulation of the model and the objective functions shall be explained.

\section{Model formulation}

\section{Equations and constraints}

The following equations and constraints are included in the proposed model: water balance constraint at node $a(E q .1)$; upper and lower limits of allocated water volume for demand $k$ at time $t(E q .2)$; upper and lower limits of shortage parameter (Eq. 3); the formula of calculation the minimum acceptable volume of supplying demand $k$ at time $t$ (Eq. 4); water balance constraint at reservoir d (Eq. 5); upper and lower limits of reservoir $d$ at time $t(E q .6)$; the upper limit of reservoirs' outflow volume in a month ( $E q$. 7); the formula of calculation the return flow volume from demand $\mathrm{k}$ at time $\mathrm{t}$ to surface water (Eq. 8). 


$$
\begin{aligned}
& S W_{a, t}+\sum_{t} \sum_{b \in U P_{a}} Q(b, a, t)=\sum_{t} \sum_{e \in D W_{a}} R(a, e, t)+\sum_{t} \sum_{k \in k_{a}} X(a, k, t) \quad \forall a, t \quad \text { (Eq.1) } \\
& X_{\min }(k, t) \leq X(k, t)+X_{s h}(k, t) \leq \operatorname{dem}(k, t) \quad \forall k, t \quad \text { (Eq.2) } \\
& 0 \leq X_{s h}(k, t) \leq X_{\min }(k, t) \quad \forall k, t \quad \text { (Eq.3) } \\
& X_{\min }(k, t)=\alpha \times \operatorname{dem}(k, t) \quad \forall k, t \quad \text { (Eq.4) } \\
& S(d, t)=S(d, t-1)+Q(d, t)-R(d, t)-E v(d, t) \quad \forall d, t \quad(\mathrm{Eq} .5) \\
& S_{\min }(d) \leq S(d, t) \leq S_{\max }(d) \quad \forall d, t \quad \text { (Eq.6) } \\
& R(d, t) \leq R_{\max }(d) \quad \forall d, t \quad \text { (Eq.7) } \\
& Q(k, a, t)=X(k, t) \times \operatorname{Ret}(k, t) \quad ; k \in U P_{a} \quad \forall d, t \quad \text { (Eq.8) }
\end{aligned}
$$

where

$a, b, e$ : the index of nodes

$d$ : the index of reservoirs

$\operatorname{dem}(k, t)$ : the water need of demand $\mathrm{k}$ in the month $\mathrm{t}$

$D W_{a}$ : the set of nodes in the downstream of $a$

$E v(d, t)$ : the amount of water evaporation in the reservoir $\mathrm{d}$ in the month $\mathrm{t}$

$k$ : the index of water demand nodes

$K_{a}$ : the set of demand nodes that get water from the node a

$l k$ : the index of Lake Urmia

$Q$ : the volume of water inflow to the reservoir $\mathrm{d}$ in the month $\mathrm{t}$

$Q(d, t)$ : the volume of water inflow to the reservoir $\mathrm{d}$ in the month $\mathrm{t}$

$R(d, t)$ : the volume of water discharged from the reservoir $\mathrm{d}$ in the month $\mathrm{t}$

$R_{\max }(d)$ : the maximum output volume capacity from reservoir $\mathrm{d}$ in a period of one month

$\operatorname{Ret}(k, t)$ : the return water ratio from the demand $\mathrm{k}$ to the allocated amount in month $\mathrm{t}$ $(\%)$

$S(d, 0)$ : the initial volume of water stored in reservoir $\mathrm{d}$

$S(d, t)$ : the volume of water present in reservoir $\mathrm{d}$ in the month $\mathrm{t}$

$S_{\max }(d, t)$ : the maximum storage capacity of reservoir d

$S_{\min }(d)$ : the initial volume of water stored in reservoir d

$S w_{a, t}$ : the volume of surface water produced at a distance of node a and its upstream nodes in the month $\mathrm{t}$

$t$ : the index of the time step

$U p_{a}$ : the set of nodes in the upstream of a

$X(a, k, t)$ : the allocated water volume from node $\mathrm{a}$ to node $\mathrm{b}$ in the month $\mathrm{t}$ $\left(k \in K_{a}, t \in T\right)$

$X(k, t)$ : the water allocated for the requirements of node $\mathrm{k}$ in the month $\mathrm{t}$

$X_{s h}(k, t)$ : the difference between the minimum acceptable and allocated water to demand $\mathrm{k}$ in month $\mathrm{t}$

In Equation 4 the parameter $\alpha$ is determined based on experts' opinions and is equal to $80 \%, 60 \%, 50 \%$ and $40 \%$ for the domestic, industrial, environmental and agricultural 
sectors respectively. Likewise, the Equation 9 has been proposed to estimate the environmental water requirements of Lake Urmia:

$$
E D_{l k}=T E D_{l k} \times \omega
$$

where $\mathrm{TED}_{\mathrm{lk}}$ is the total environmental demand for Lake Urmia per year (million $\mathrm{m}^{3}$ ) which was caculated in the past study; $\mathrm{ED}_{\mathrm{lk}}$ is the part of environmental demand of the lake which must be supplied by the sub-basins of the Zarrineh River and Simineh River (million $\mathrm{m}^{3}$ ); $\omega$ is the share of Zarrineh and Simineh rivers in surface water reaching to the Lake Urmia (\%). Indeed by means of above equation, the share of case study area in the supplying of surface wate resources for Lake Urmia will be calculated.

According to the past research, in the abovementioned equation $\mathrm{TED}_{\mathrm{lk}}$ is equal to 3,086 million $\mathrm{m}^{3}$ (Abbaspour and Nazaridoust, 2007), and based on the reported data by the Iranian Ministry of Energy, 52\% $(\omega)$ of the inflow surface water to Lake Urmia is supplied by the Zarrineh and Simineh rivers in the long-term period. Hence, the ED ${ }_{\mathrm{lk}}$ value is equivalent to 1605 million $\mathrm{m}^{3}$.

\section{Objective functions}

Objective 1: The first objective function is developed to meet the needs of water consumption sectors as well as to satisfy the environmental demand of the rivers, in which each stakeholder has a certain relative priority. These priorities, which are characterized by applying relative weight coefficients to each section, are proposed according to the experts' opinions as the values offered in Table 1.

Table 1. Relative weights of water demand sectors

\begin{tabular}{c|c|c|c|c} 
Sector & Agriculture & Industry & Rivers' Environment & Domestic \\
\hline Relative weight $\left(\gamma_{\mathrm{i}}\right)$ & 1 & 5 & 10 & $\mathbf{5 0}$
\end{tabular}

The first objective function is defined in terms of the total percentage supplied for the various sections according to their relative weight; and its equation is as follows (Eq. 10):

$$
Z_{1}=\sum_{i} \gamma_{i} \times \sup _{i}
$$

The more quantity of this function will be more favorable. In the abovementioned relation $\gamma_{i}$ is the weight of section $i$ and $\sup _{i}$ is the annual percentage of supplied demand for section $i$ throughout the entire case study area and is computed according to Equation 11:

$$
\sup _{i}=\frac{\sum_{k i} \sum_{t} x(k i, t)}{\sum_{k i} \sum_{t} \operatorname{dem}(k i, t)}
$$

where ki is the index of demand nodes of section $\mathrm{i}$; $\mathrm{X}(\mathrm{ki}, \mathrm{t})$ is the amount of allocated water to ki in the month $\mathrm{t}$. 
Objective 2: The second objective function is to consider the economic aspect of water resources management in the catchment area and represents the total net cost of water allocation to the different sectors. It is expressed as follows (Eq. 12):

$$
Z_{2}=\sum_{t} \sum_{k}\left(\left(C_{k, t}-G_{k, t}\right) \times X_{k, t}\right)
$$

where $C_{k, t}$ is the cost of allocating a unit of water for the demand of $k$ in the month $t$; $G_{k, t}$ is revenues from the sale of water for the demand $k$ in the month $t$ (water tariff); $X_{k, t}$ is volume of water allocated for the demand of $\mathrm{k}$ in the month $\mathrm{t}$. Therefore, the smaller, the abovementioned objective is in amount, it is more appropriate and the results will be closer to the optimal response.

Objective 3: As illustrated in Equation 3, in order to avoid the infeasibility of the optimization model in severe drought conditions, where meeting the minimum requirements for the entire sectors is not possible, the water shortage parameter is defined, which, in the lack of the presence of sufficient resources in order to satisfy the minimum acceptable supply level of each demand node, at a time or in several series of time, this parameter shall get a positive amount. It is obvious that, in the optimum mode, all the values of this parameter must be nil or as small as possible. Hence, the function of $\mathrm{Z}_{3}$ which illustrates the sum of these parameters values, is developed as a one the objectives of the model, so by minimizing its value the better results will be achieved (Eq. 13).

$$
Z_{3}=\sum_{t} \sum_{k}\left(X_{s h}(k, t)\right)
$$

According to above explanations and objective functions formulation, the optimal results of the developed model will be achieved by maximizing the $Z_{1}$ as well as minimizing the $Z_{2}$ and $Z_{3}$ values. In order to convert the three-objective model to a single-objective one, the $\mathrm{CP}$ method was applied which is introduced below.

\section{Compromise programming}

Compromise Programming (CP) is one of the most commonly used methods for converting multi-objective into a single-objective problem, which has been successful in the past studies of water resource planning (Fattahi and Fayyaz, 2010; Roozbahani et al., 2015; Shiau and Lee, 2005). Thereby, in the present research by using this method, the multi-objective model becomes a single-objective model and then the prospects of assigning different weights for objective functions and a change in the risk parameter (p) are accomplished and solved by the GAMS software and using CONOPT solver (Brooke et al., 1998). This method is based on decreasing the distance between the final solution and the ideal response. Its advantages are possibility to weigh the varied objectives and taking into consideration the risk taking as well as the risk aversion approaches. The general form of CP equation is expressed as follows (Eq. 14): 


$$
D_{p}(x)=\left[\sum_{y=1}^{n_{y}} w_{y}^{p} \cdot \bar{\beta}_{y}^{p}\right]^{1 / p}
$$

In the abovementioned equation, $\bar{\beta}_{y}$ represents the normalized value of the objective function $\mathrm{y} . w_{y}$ denotes the weight of each function and $\mathrm{p}$ is a positive parameter which designates the decision-maker's risk involvement. The smaller $\mathrm{p}$ value shows that the decision-maker have placed greater importance on small deviations from ideal point which indicates adopting risk aversion approach; whereas, the larger this parameter is, expresses a vaster and higher risk taking by the decision-maker, such that greater deviations shall have more importance in determining the $\mathrm{Dp}(\mathrm{x})$ value. In order to normalize the value of the objective functions of a given set of responses, the following relation is utilized (Eq. 15):

$$
\bar{\beta}_{y}=\left(\frac{Z_{y}^{*}-Z_{y}(x)}{Z_{y}^{*}-Z_{y}^{*}}\right)
$$

where $Z_{y}^{*}$ andthe worst possible values, for the objective function are the best and $Z_{y}^{*}$ $Z_{y}$. For example, if the aim is to maximize $Z_{y}$, its most possible largest value, shall be the best amount and its smallest possible value shall also be the worst response.

As mentioned above, in the given equation, the parameter $w_{y}$ denotes the relative weight of the objective function $y$ and the parameter $\mathrm{p}$ demonstrates the degree of risks involved in the management of resources. So as to determine the optimal response, the various values of $\mathrm{p}(p \in P)$, together with the different weight sets, were put to test in Equation 14.

$$
P=\{1,2,3,4, \ldots, 99,100\}
$$

In order to produce varied sets of weights, 3 members are selected from a set of $\mathrm{K}$ which includes 18 different numbers in the range of 0.05 to 0.9 - on the condition that, their summation is equivalent to 1 . It should be noted that, the smallest weight value is assumed equal to 0.05 . Since the sum of the weights of the three objective functions is equal to 1, thereby, the largest possible value for the weight of each function will be equivalent to 0.9 .

$$
K=\{0.05,0.1,0.15, \ldots, 0.85,0.9\}
$$

Principled on the above descriptions, the 171 various sets of weights are produced. After the implementation of the model, with the each series of weights and different values of $p$, the results obtained, and initially assessed. This determined that, the results of using all of the weights series for domestic, industrial and rivers' environmental sectors were acceptable for at least one of the values of $p$, in which the minimum acceptable of water supplying in these sectors were satisfied.

Though, in the agricultural sector, in the case that, the weight of the cost function (second objective function) is equivalent to or greater than 0.2 , for the all values of $p$, the supplying level was less than $40 \%$, which is lower than the minimal acceptable 
supply level. Therefore, with due attention to the fact that the second objective function must get one of the following values, such as 0.05 and 0.1 or 0.15 , only 51 varied series of weights will be acceptable and surveyed in continuation. In Table 2, the weighted coefficient of the objective function are shown in each of n-series of weight including series of weight 1(SW1) to series of weight 51(SW51).

Table 2. Values of weights of the objective functions in varied weight series

\begin{tabular}{|c|c|c|c|c|c|c|c|}
\hline \multirow[b]{2}{*}{ SWN } & \multicolumn{3}{|c|}{ Values of relative weights } & \multirow[b]{2}{*}{ SWN } & \multicolumn{3}{|c|}{ Values of relative weights } \\
\hline & $\begin{array}{c}\text { Z1 } \\
\text { (SUPPLY) }\end{array}$ & $\begin{array}{c}\mathrm{Z2} \\
(\mathrm{COST})\end{array}$ & $\begin{array}{c}\text { Z3 } \\
\text { (SHORTAGE) }\end{array}$ & & $\begin{array}{c}\text { Z1 } \\
\text { (SUPPLY) }\end{array}$ & $\begin{array}{c}\mathrm{Z2} \\
(\mathrm{COST})\end{array}$ & $\begin{array}{c}\text { Z3 } \\
\text { (SHORTAGE) }\end{array}$ \\
\hline SW1 & 0.05 & 0.05 & 0.9 & SW27 & 0.45 & 0.1 & 0.45 \\
\hline SW2 & 0.1 & 0.05 & 0.85 & SW28 & 0.5 & 0.1 & 0.4 \\
\hline SW3 & 0.15 & 0.05 & 0.8 & SW29 & 0.55 & 0.1 & 0.35 \\
\hline SW4 & 0.2 & 0.05 & 0.75 & SW30 & 0.6 & 0.1 & 0.3 \\
\hline SW5 & 0.25 & 0.05 & 0.7 & SW31 & 0.65 & 0.1 & 0.25 \\
\hline SW6 & 0.3 & 0.05 & 0.65 & SW32 & 0.7 & 0.1 & 0.2 \\
\hline SW7 & 0.35 & 0.05 & 0.6 & SW33 & 0.75 & 0.1 & 0.15 \\
\hline SW8 & 0.4 & 0.05 & 0.55 & SW34 & 0.8 & 0.1 & 0.1 \\
\hline SW9 & 0.45 & 0.05 & 0.5 & SW35 & 0.85 & 0.1 & 0.05 \\
\hline SW10 & 0.5 & 0.05 & 0.45 & SW36 & 0.05 & 0.15 & 0.8 \\
\hline SW11 & 0.55 & 0.05 & 0.4 & SW37 & 0.1 & 0.15 & 0.75 \\
\hline SW12 & 0.6 & 0.05 & 0.35 & SW38 & 0.15 & 0.15 & 0.7 \\
\hline SW13 & 0.65 & 0.05 & 0.3 & SW39 & 0.2 & 0.15 & 0.65 \\
\hline SW14 & 0.7 & 0.05 & 0.25 & SW40 & 0.25 & 0.15 & 0.6 \\
\hline SW15 & 0.75 & 0.05 & 0.2 & SW41 & 0.3 & 0.15 & 0.55 \\
\hline SW16 & 0.8 & 0.05 & 0.15 & SW42 & 0.35 & 0.15 & 0.5 \\
\hline SW17 & 0.85 & 0.05 & 0.1 & SW43 & 0.4 & 0.15 & 0.45 \\
\hline SW18 & 0.9 & 0.05 & 0.05 & SW44 & 0.45 & 0.15 & 0.4 \\
\hline SW19 & 0.05 & 0.1 & 0.85 & SW45 & 0.5 & 0.15 & 0.35 \\
\hline SW20 & 0.1 & 0.1 & 0.8 & SW46 & 0.55 & 0.15 & 0.3 \\
\hline SW21 & 0.15 & 0.1 & 0.75 & SW47 & 0.6 & 0.15 & 0.25 \\
\hline SW22 & 0.2 & 0.1 & 0.7 & SW48 & 0.65 & 0.15 & 0.2 \\
\hline SW23 & 0.25 & 0.1 & 0.65 & SW49 & 0.7 & 0.15 & 0.15 \\
\hline SW24 & 0.3 & 0.1 & 0.6 & SW50 & 0.75 & 0.15 & 0.1 \\
\hline SW25 & 0.35 & 0.1 & 0.55 & SW51 & 0.8 & 0.15 & 0.05 \\
\hline SW26 & 0.4 & 0.1 & 0.5 & & & & \\
\hline
\end{tabular}

The CP model is solved for all of the series of weights and varied values of $p$ from 1 to 100. Now, with due attention to the fact that, satisfying the environmental water requirements for Lake Urmia is one of the most important issues under consideration, so the final result should be able to satisfy the requirements of the various sectors and also that of the lake to the most possible level. Given that, the amount for domestic and industrial demand is very much lower than that of the agricultural sector, and meeting of domestic and industrial requirements has always been of high priority from the viewpoint of decision-makers (Table 1), in all cases (i.e. in the all series of weights and the different amounts of the p), these sectors have been satisfied at a desirable level. 
Similarly, due to the high volume of consumption in the agricultural sector there is competitiveness and a major dispute between this sector and Lake Urmia. Hence, by rendering a new method, efforts have been made to signify the equilibrium point between these two sectors, which is identified as the optimal response of the model.

In order to establish a balance between the agricultural sector and the Lake Urmia, the utility function in both the sections have been defined (Eq. 16) then, by plotting the graphs of the utility and $\mathrm{p}$ against each other for the both of them, in the same coordinate system, the intersection points of the two mentioned graphs identified, which in fact, is the point of equilibrium between the agricultural and lake environmental demand. Some of the weights series have a just one intersection point, whilst some others have several intersection points. In the case that, the graphs have more than one intersection point, the point which displays the highest utility is introduced as the point of equilibrium. The utility function equation for the agricultural sector and Lake Urmia has been proposed as follows:

$$
f_{i}\left(x_{i}\right)=\left\{\begin{array}{lll}
0 & , & x<x_{i, \min } \\
\frac{x_{i}-x_{i, \min }}{\operatorname{Dem}_{i}-x_{i, \min }} & , & x \geq x_{i, \min }
\end{array}\right.
$$

In the abovementioned relation, $x_{i}$ is the annual amount allotted to, and $D_{e m}$ and is the annual demand of sector $i$. Moreover, $x_{i, \min }$ also is the minimum acceptable amount for each sector that must be allotted annually. In Figure 2, the utility changes of the agricultural sector and Lake Urmia are illustrated in relative to the impacts of changes of $\mathrm{p}$ in the CP method using SW1 (\{0.05, 0.05, 0.9\}).

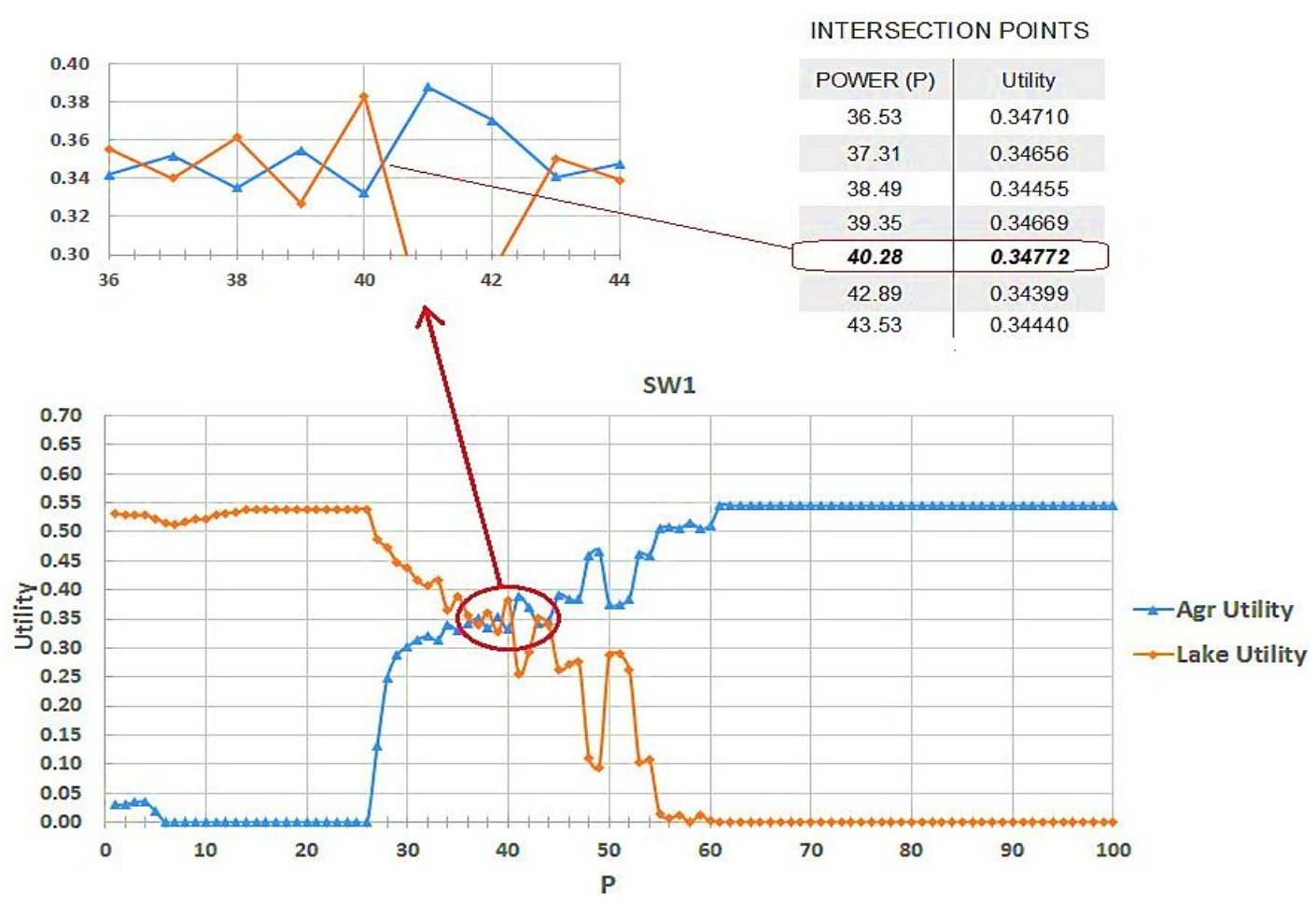

Figure 2. Variation of utility in the agricultural sector and environmental water requirements of the lake for different $p$ by use of SWI 
Likewise, the characteristics of the utility intersections of these two sections are shown alongside the graph. According to this diagram, there are 7 equilibrium points for this series of weights. From amongst these points the most desirable condition shall be selected. In this case (SW1) the $p$ and utility values in the optimal point of equilibrium, equates to 40.28 and 0.3477 respectively. For the entire 51 series weight, the above method was performed and each of the equilibrium points specified.

In addition to SW1 conditions which are shown in Figure 2, the utility changes using SW5, SW10, SW20, SW30, SW40 and SW50 for various $p$ are demonstrated in Figure 3.
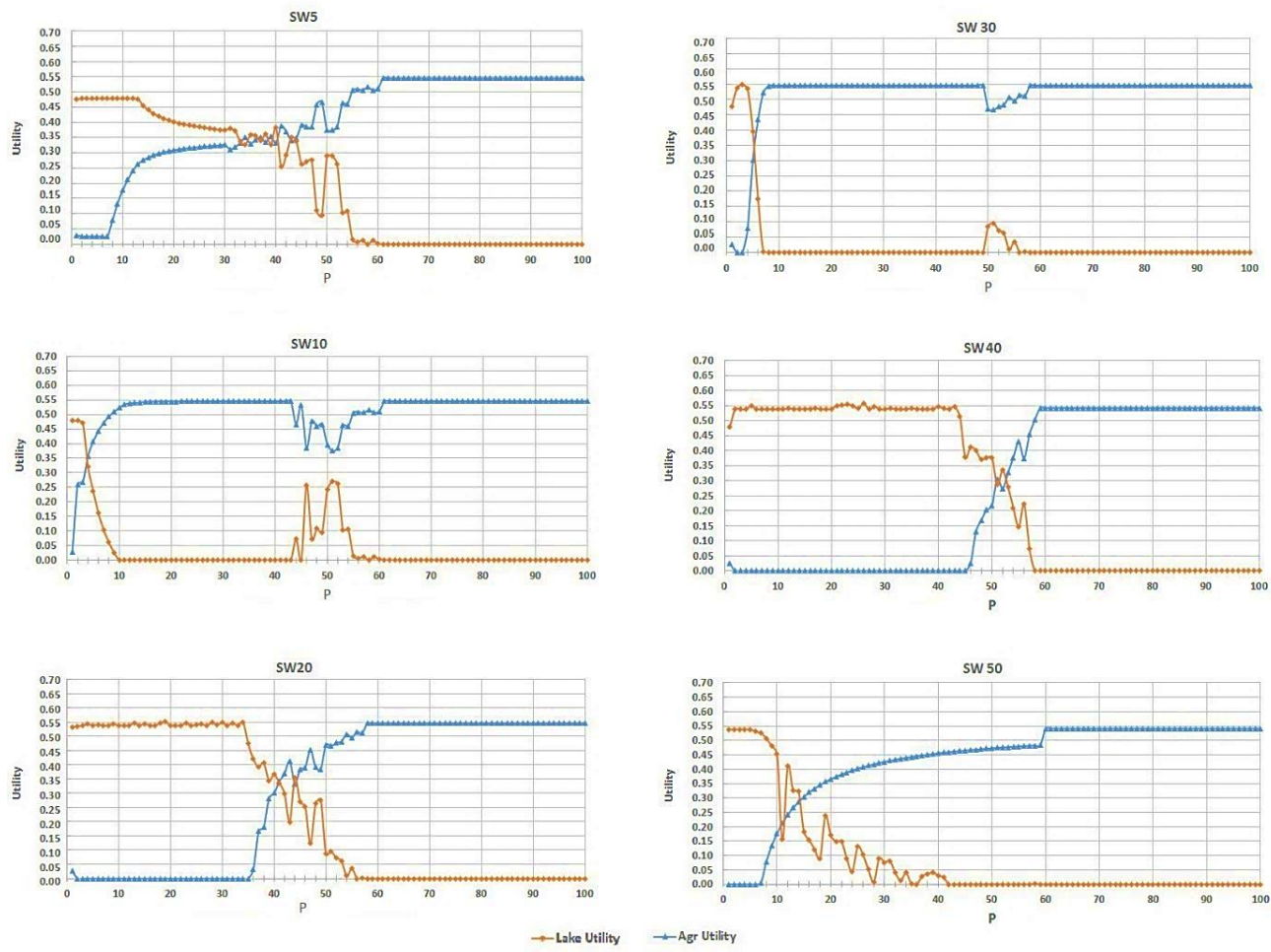

Figure 3. Variations of utility in the agricultural sector and Lake Urmia for different $P$ and series weight: SW5, SW50, SW40, SW30, SW20 and SW10

\section{Results and discussion}

In Table 2, for each set of weights, the amount of $\mathrm{p}$ and the corresponding utility value are specified at the equilibrium point. In accordance with the results rendered, the utility value varies from 0.23 to 0.3477 for various situations. The equilibrium point which creates the highest amount of utility in both of the sectors shall be selected as the final approach. As can be observed in Table 3, the set of weights of 1 to 5 have of the same equilibrium points that indicates the highest utility value. Thereby, the results of $\mathrm{CP}$ model with the $\mathrm{P}=40.28$ and with abovementioned sets of weights for objective functions (SW1 to SW5) are introduced as the optimal resource allocation approach which indicate Utility of 0.3477 for agricultural and lake's environment. According to various sets of weights given for the objective functions in Table 2, in the sets of 1 to 5 , the economic function's weight in all the five conditions is equivalent to 0.05 , the shortage function's weight varies from 0.7 to 0.9 and the supply function's alters from 
0.05 to 0.25 . The results indicated that, the weight of the economic function plays a crucial role in the results of the CP model and its change will have a greater impact on the result, rather than the change in the weight of supply function or shortage function. Similarly, in all the sets of weights, an increment in the value of $p$ from 60 to 100, the utility of the agricultural sector gains its maximum amount and the utility of the lake gets to its minimum. By decreasing in the $\mathrm{p}$ value (adopting the risk aversion approach) this process has been reversed in the various sets of weight, such that, the utility of the agricultural sector will be lower than the utility of the lake's environment. Hence, on the basis of the results, by increasing the level of risk taking, the higher level of agricultural demand supplying will be achieved.

Table 3. The values of the risk parameter and the utility at the equilibrium points in the different sets of weight

\begin{tabular}{|c|c|c|c|c|c|}
\hline \multirow{2}{*}{ SWN } & \multicolumn{2}{|c|}{ Intersection point } & \multirow{2}{*}{ SWN } & \multicolumn{2}{|c|}{ Intersection point } \\
\hline & $\mathbf{P}$ & Utility & & $\mathbf{P}$ & Utility \\
\hline SW1 & 40.28 & 0.3477 & SW27 & 42.36 & 0.2796 \\
\hline SW2 & 40.28 & 0.3477 & SW28 & 15.79 & 0.3163 \\
\hline SW3 & 40.28 & 0.3477 & SW29 & 7.80 & 0.3353 \\
\hline SW4 & 40.28 & 0.3477 & SW30 & 5.26 & 0.3366 \\
\hline SW5 & 40.28 & 0.3477 & SW31 & 4.06 & 0.3429 \\
\hline SW6 & 43.53 & 0.3444 & SW32 & 3.35 & 0.3136 \\
\hline SW7 & 43.53 & 0.3444 & SW33 & 2.80 & 0.3039 \\
\hline SW8 & 5.90 & 0.3440 & SW34 & 2.51 & 0.2339 \\
\hline SW9 & 4.66 & 0.3440 & SW35 & 2.45 & 0.2493 \\
\hline SW10 & 3.84 & 0.3440 & SW36 & 52.55 & 0.3031 \\
\hline SW11 & 3.35 & 0.3437 & SW37 & 52.55 & 0.3031 \\
\hline SW12 & 2.75 & 0.3439 & SW38 & 52.55 & 0.3031 \\
\hline SW13 & 2.49 & 0.3421 & SW39 & 52.55 & 0.3031 \\
\hline SW14 & 2.28 & 0.3386 & SW40 & 52.55 & 0.3031 \\
\hline SW15 & 1.95 & 0.3370 & SW41 & 52.55 & 0.3031 \\
\hline SW16 & 1.57 & 0.2763 & SW42 & 52.44 & 0.2976 \\
\hline SW17 & 1.44 & 0.2516 & SW43 & 52.39 & 0.2916 \\
\hline SW18 & 1.27 & 0.3355 & SW44 & 53.00 & 0.2848 \\
\hline SW19 & 44.16 & 0.3418 & SW45 & 53.47 & 0.2753 \\
\hline SW20 & 44.16 & 0.3418 & SW46 & 54.27 & 0.2749 \\
\hline SW21 & 44.16 & 0.3418 & SW47 & 54.97 & 0.2777 \\
\hline SW22 & 44.16 & 0.3418 & SW48 & 54.96 & 0.2741 \\
\hline SW23 & 44.16 & 0.3418 & SW49 & 41.08 & 0.2748 \\
\hline SW24 & 44.16 & 0.3418 & SW50 & 14.23 & 0.2904 \\
\hline SW25 & 44.16 & 0.3418 & SW51 & 8.39 & 0.2821 \\
\hline SW26 & 44.16 & 0.3418 & & & \\
\hline
\end{tabular}


The results relative to the allocation of the various sectors in the proposed conditions have been rendered in Table 4. According to these results, the amount allotted to the domestic sector is $92.3 \%$ and that of the industrial sector is $100 \%$. Similarly, the minimum environmental demand of the rivers has been estimated as $100 \%$. The reason for the high level of supply of the industrial sector in comparison with the domestic sector, despite its smaller relative priority, is the lower demand of that sector (29 million $\mathrm{m}^{3}$ ) than domestic one $\left(331\right.$ million $\left.\mathrm{m}^{3}\right)$. It should be mentioned that in the proposed approach, the amount of the annual flow of rivers has been more than their environmental demand. This may be due to cost minimizing and attempts to increase inflow water into the Lake Urmia during equilibration process between agriculture and the environment. Moreover as it shown in the Table 4, satisfying level of the agricultural sector is about $61 \%$, which may be cause of economic concerns. Hence, in order to avoid unfavorable economic consequences, the water savings policies must be considered. For example adopting suitable cultivation patterns and using more efficient irrigation systems could be helpful methods.

Table 4. The percentage of supply of the various sectors and volume of water allocated to each section in the case study area

\begin{tabular}{c|c|c|c|c}
\hline & Domestic & Industry & Agriculture & Lake Urmia \\
\hline Demand volume (million m ${ }^{3}$ ) & 331 & 29 & 2300 & 1605 \\
Supply level (\%) & $92.3 \%$ & $100 \%$ & $60.8 \%$ & $67.45 \%$ \\
Allocated volume (mcm) & 305.5 & 29 & 1398 & 1082 \\
\hline
\end{tabular}

Likewise, in accordance with Figure 4, in the specified weight of the cost function, if the weight of the shortage function (the third objective function) is greater than the supply function (the first objective function), the utility value will be around its optimal value (i.e. utility value in the equilibrium point). By increasing the weight of the economic function from 0.05 to 0.1 and also from 0.1 to 0.15 , the maximum value of the utility in the equilibrating point between the two sections becomes smaller. This is such that, by choosing $0.05,0.1$ and 0.15 as the weight of cost function, the amount of utility attained at the optimal equilibrium point equates to $0.3477,0.3429$ and 0.3030 respectively.

The present paper's output is a situation in which the main parties of a conflict reach to equilibrium. In this status the optimal value of risk parameter in the CP method could be found, in which the main parties of the dispute agree on a specific utility level. In other words, when the risk parameter is not equal to optimal value (i.e. risk parameter in the equilibrium point), the utility level of one part will be greater than the other one, so arising conflicts are possible. The results show that by changing in the level of decision makers' risk appetite, the stakeholders can reach an agreement and also reduce their conflicts. Moreover, through applying the $\mathrm{CP}$ technique the various objectives or concepts of sustainable water resource management including economic, environmental and social preferences are taken into account simultaneously. Consequently the introduced methodology could support the sustainability of water resource system. 

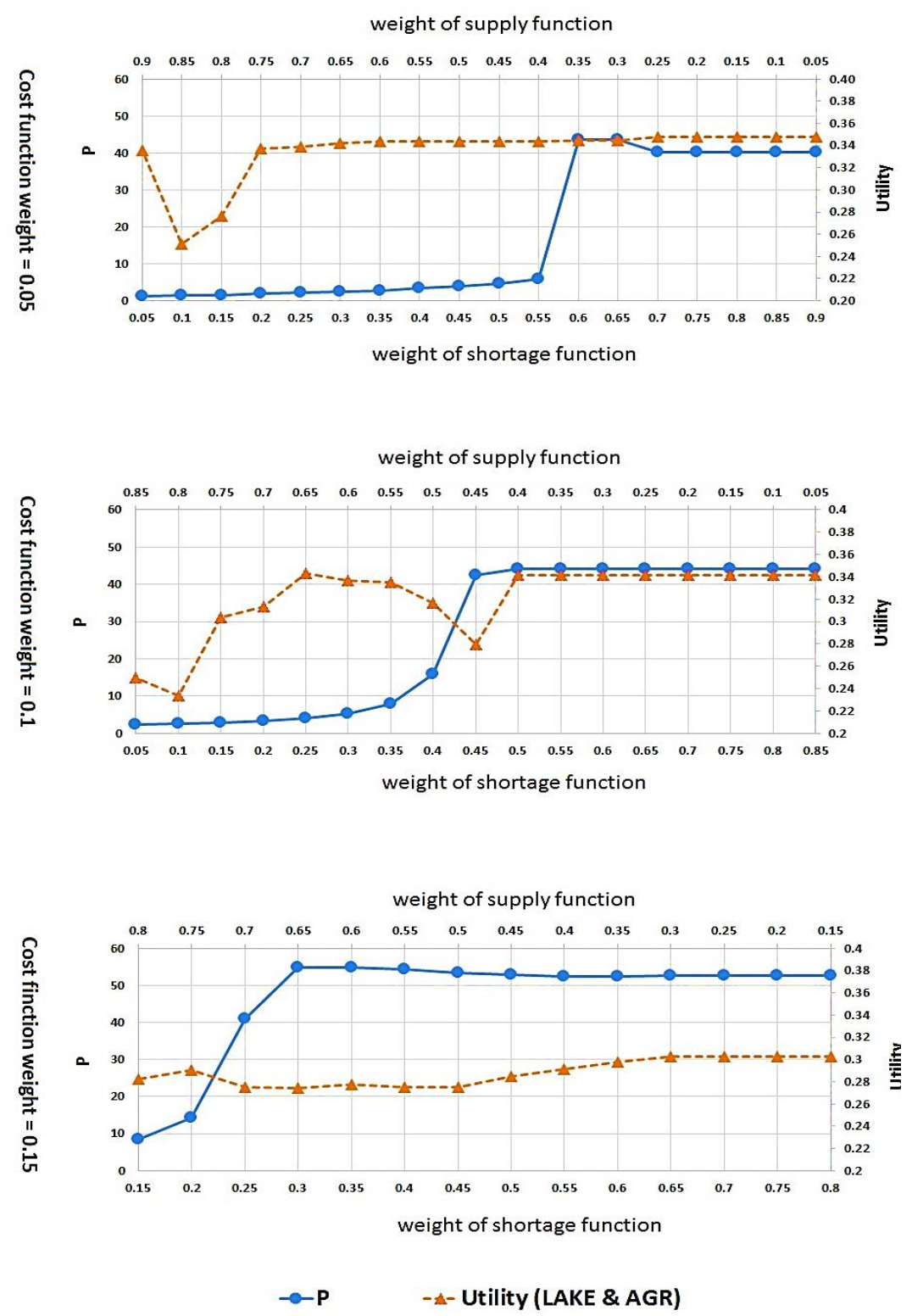

Figure 4. the value of risk parameters and utility in the equilibrium points for various weights of the objective functions

\section{Conclusion}

In this research, a multi-objective optimization model for the allocation of surface water resources is presented in the river-lake connected basins. This model addresses the socio-economic and environmental aspects of water resource management as the key factors of the sustainability, and also considers the ecological requirements of rivers and the environmental water demand of the lake. The model is implemented in the Zarrineh and Simineh rivers sub-basins in the southern part of the Lake Urmia basin in Iran. The proposed model was solved using the $\mathrm{CP}$ technique and several responses were generated by assuming 171 different sets of weights for the objective functions and assigning 100 different values for the risk parameter (p). Overviewing the results of the CP model showed that 120 of 171 produced sets of weights must be eliminated due to unacceptable deficit value in the agricultural sector. Hence, 51 various sets of weights 
were analyzed in detail to reach an optimal approach. To reduce competition between the Lake's environmental demand and agricultural sector -as the main rival of the Lake Urmia- the equilibrium points between these two competitors are found for each set of weighs through drawing the graph of utility vs $\mathrm{p}$. These points illustrate the equal utility level for both sectors. This issue helps to reduce conflicts between them, because by increasing the utility degree on one side in comparison to its value in the equilibrium point, the other side's utility will be decrease, and it can be the cause of dissatisfaction. The equilibrium point that indicates the largest utility level for the agricultural and the lake is selected as the best point. The results of model in the condition of the best equilibrium point, support the water resources sustainability, and simultaneously provide desirable level of utility for all stakeholders.

Furthermore, in formulation of the presented model the priority of the sectors to each other, as well as the minimum acceptable supply level of stakeholders are taken into account. Moreover, the water demand growth in future and reduction of available water resource due to climate change impacts under pessimistic scenario are considered. According to the results, the supply level of domestic is $92.3 \%$ and the industrial one is $100 \%$ which are favorable values. The results show that adoption of risk taking approach is in line with satisfying the demand of the sectors with lower priority like agricultural sector in this research.

The proposed method can be used to manage water resources in the river-lake systems and reduce the interaction between the environmental supporters and cultivators or between the other sectors are in conflicts, through the agreement of the parties on the equilibrium point.

\section{REFERENCES}

[1] Abbaspour, K. C, Faramarzi, M., Ghasemi, S. S., Yang, H. (2009): Assessing the impact of climate change on water resources in Iran. - Water Resources Research 45(10).

[2] Abbaspour, M., Nazaridoust, A. (2007): Determination of environmental water requirements of lake Urmia, Iran: An ecological approach. - International Journal of Environmental Studies 64(2): 161-169.

[3] Acreman, M., Arthington, A. H., Colloff, M. J., Couch, C., Crossman, N. D., Dyer, F., Young, W. (2014): Environmental flows for natural, hybrid, and novel riverine ecosystems in a changing world. - Frontiers in Ecology and the Environment 12(8): 466473.

[4] Aghakhani, M., Nasrabadi, T., Vafaeinejad, A. (2018): Assessment of the effects of land use scenarios on watershed surface runoff using hydrological modelling. - Applied Ecology and Environmental Research 16(3): 2369-2389. DOI: 10.15666/aeer/1603_23692389.

[5] AghaKouchak, A., Norouzi, H., Madani, K., Mirchi, A., Azarderakhsh, M., Nazemi, A., Hasanzadeh, E. (2015): Aral sea syndrome desiccates Lake Urmia: Call for action. Journal of Great Lakes Research 41(1): 307-311.

[6] Alipour, H., Olya, H. G. T. (2015): Sustainable planning model toward reviving lake urmia. - International Journal of Water Resources Development 31(4): 519-539.

[7] Barnett, T. P., Pierce, D. W., Hidalgo, H. G., Bonfils, C., Santer, B. D., Das, T., Mirin, A. A. (2008): Human-induced changes in the hydrology of the western united states. Science 319(5866): 1080-1083.

[8] Bazargan-Lari, M. R., Kerachian, R., Mansoori, A. (2009): A conflict-resolution model for the conjunctive use of surface and groundwater resources that considers water-quality issues: A case study. - Environmental Management 43(3): 470-482. 
[9] Braga, B. P. F. (2001): Integrated urban water resources management: A challenge into the 21st century. - International Journal of Water Resources Development 17(4): 581599.

[10] Brooke, A., Kendrick, D., Meeraus, A., Raman, R., America, U. (1998): The General Algebraic Modeling System. GAMS 1050. - GAMS Development Corporation, Fairfax, VA, USA.

[11] Can, E. K., Houck, M. H. (1984): Real-time reservoir operations by goal programming. Journal of Water Resources Planning and Management 110(3): 297-309.

[12] Emam, A. R., Kappas, M., Hosseini, S. Z. (2015): Assessing the impact of climate change on water resources, crop production and land degradation in a semi-arid river basin. Hydrology Research 46(6): 854-870.

[13] Fattahi, P., Fayyaz, S. (2010): A compromise programming model to integrated urban water management. - Water Resources Management 24(6): 1211-1227.

[14] Hassanzadeh, E., Zarghami, M., Hassanzadeh, Y. (2012): Determining the main factors in declining the Urmia Lake level by using system dynamics modeling. - Water Resources Management 26(1): 129-145.

[15] IPCC (2007): Climate change 2007: The Physical Science Basis. - In: Solomon, D. Q. S., Manning, M., Chen, Z. M., Marquis, K. B. A., Tignor, M., Miller, H. L. (eds.) IPCC Contribution of Working Group I to the Fourth Assessment Report of the Intergovernmental Panel on Climate Change. Cambridge University Press, Cambridge.

[16] Jiang, S., Ren, L., Yong, B., Fu, C., Yang, X. (2012): Analyzing the effects of climate variability and human activities on runoff from the Laohahe Basin in northern China. Hydrology Research 43(1-2): 3-13.

[17] Kao, C. (2010): Weight determination for consistently ranking alternatives in multiple criteria decision analysis. - Applied Mathematical Modelling 34(7): 1779-1787.

[18] Lee, K. E., Shahabudin, S. M., Mokhtar, M., Choy, Y. K., Simon, N. (2018): Sustainable water resources management and potential development of multi-purpose dam: The case of Malaysia. - Applied Ecology and Environmental Research 16(3): 2323-2347. DOI: 10.15666/aeer/1603_23232347.

[19] Madani, K. (2014): Water management in Iran: What is causing the looming crisis? Journal of Environmental Studies and Sciences 4(4): 315-328.

[20] Madani, K., Zarezadeh, M., Morid, S. (2014): A new framework for resolving conflicts over transboundary rivers using bankruptcy methods. - Hydrology and Earth System Sciences 18(8): 3055-3068.

[21] Mao, J., Zhang, P., Dai, L., Dai, H., Hu, T. (2016): Optimal operation of a multi-reservoir system for environmental water demand of a river-connected lake. - Hydrology Research 47(S1): 206-224.

[22] MGC (2012): National Water Master Plan Study: The Lake Urmia Basin. - MGC 4.

[23] Mianabadi, H., Mostert, E., Zarghami, M., van de Giesen, N. (2014): A new bankruptcy method for conflict resolution in water resources allocation. - Journal of Environmental Management 144: 152-159.

[24] Omer, A., Wang, W., Basheer, A. K., Yong, B. (2017): Integrated assessment of the impacts of climate variability and anthropogenic activities on river runoff: A case study in the Hutuo River Basin, China. - Hydrology Research 48(2): 416-430.

[25] Oxley, R. L., Mays, L. W., Murray, A. (2016): Optimization model for the sustainable water resource management of river basins. - Water Resources Management 1-18.

[26] Poff, N. L., Brown, C. M., Grantham, T. E., Matthews, J. H., Palmer, M. A., Spence, C. M., et al. (2015): Sustainable water management under future uncertainty with ecoengineering decision scaling. - Nature Climate Change 6: 25-34.

[27] Prakash, O., Srinivasan, K., Sudheer, K. P. (2015): Adaptive multi-objective simulationoptimization framework for dynamic flood control operation in a river-reservoir system. - Hydrology Research 46(6): 893-911. 
[28] Salazar, R., Szidarovszky, F., Coppola, E. Jr., Rojano, A. (2007): Application of game theory for a groundwater conflict in Mexico. - Journal of Environmental Management 84(4): 560-571.

[29] Roozbahani, R., Schreider, S., Abbasi, B. (2013): Economic sharing of basin water resources between competing stakeholders. - Water Resources Management 27(8): 29652988.

[30] Roozbahani, R., Schreider, S., Abbasi, B. (2015): Optimal water allocation through a multi-objective compromise between environmental, social, and economic preferences. Environmental Modelling \& Software 64: 18-30.

[31] Scanlon, B. R., Jolly, I., Sophocleous, M., Zhang, L. (2007): Global impacts of conversions from natural to agricultural ecosystems on water resources: Quantity versus quality. - Water Resources Research 43(3). https://doi.org/10.1029/2006WR005486.

[32] Shakib, H. S., Shojarastegari, H. (2017): Climate change impacts and water resources management: Chehel-Chai Basin, Iran. - Applied Ecology and Environmental Research 15(4): 741-754.

[33] Shiau, J. T., Lee, H. C. (2005): Derivation of optimal hedging rules for a water-supply reservoir through compromise programming. - Water Resources Management 19(2): 111-132.

[34] Stocker, T. F., Qin, D., Plattner, G.-K., Alexander, L. V., Allen, S. K., Bindoff, N. L., Emori, S. (2013): Technical Summary Climate Change 2013: The Physical Science Basis. Contribution of Working Group I to the Fifth Assessment Report of the Intergovernmental Panel on Climate Change. - Cambridge University Press, Cambridge, UK., pp. 33-115.

[35] Torabi, P. S., Estiri, K., Hafez, B. (2010): The role of environmental requirements in process of water allocation for watersheds in Iran: Sustainable development approach. Paper presented at the 2nd International Conference Water, Ecosystems and Sustainable Development in Arid and Semi-arid Zones, Tehran.

[36] UNDP (2016): Iran Third National Communication to United Nations Framework Convention on Climate Change (UNFCCC), Chapter 4. - National Climate Change Office, Department of Environment, Tehran.

[37] Xu, X., Yang, H., Yang, D., Ma, H. (2013): Assessing the impacts of climate variability and human activities on annual runoff in the Luan River Basin, China. - Hydrology Research 44(5): 940-952.

[38] Xuan, W., Quan, C., Shuyi, L. (2012): An optimal water allocation model based on water resources security assessment and its application in Zhangjiakou Region, Northern China. - Resources, Conservation and Recycling 69: 57-65.

[39] Yang, W., Yang, Z. (2013): Development of a long-term, ecologically oriented dam release plan for the lake Baiyangdian Sub-Basin, Northern China. - Water Resources Management 27(2): 1-22.

[40] Zarghami, M., Szidarovszky, F. (2011): Multicriteria Analysis: Applications to Water and Environment Management. - Springer Science \& Business Media, Berlin. 